items according to age and gender of patients, FB characteristics and FB location, circumstances of the accident, as emerging from the ESFBI study.

Methods A retrospective study in major hospitals of 19 European countries was realised on children aged $0-14$ having inhaled/aspired or ingested a stationery item, with regard to the characteristics of the child and the FB (shape volume consistency), the FB location the hospitalisation's details and the occurrence of complications.

Results In the years 2000-2003 a total of 2094 FB injuries occurred in children aged $0-14$ years. Among them $62(3 \%)$ were due to a stationery item: 32 were due to objects insertion in the ears while 30 occurred in the upper and lower respiratory tract. Objects most frequently involved are parts of pens in children younger than 3 years and eraser in older. $39 \%$ of children needed hospitalisation. The most documented complication was inflammation of external ear. Almost $24 \%$ of injuries happened under adults supervision.

Conclusions Injuries are events that in many cases can be prevented with appropriate strategies. Passive environmental strategies, including product modification by manufacturers, are the most effective. However, regulation regarding small parts of potentially dangerous objects, covers products addressed to children use but objects not projected for children, such as stationary items, are excluded. Our study testifies that stationary is involved in a non-negligible percentage of FB injuries, mainly due to insertion in the ears. Frequently, injuries happens under adult supervision. This results confirm the fact that when passive preventive strategies are not practical, active strategies that promote behaviour change are necessary and information about this issue should be included in all visits to family paediatricians.

\section{RISK POSED TO CHILDREN BY STATIONERY ITEMS IN THE UPPER AIRWAYS: EVIDENCE EMERGING FROM THE ESFBI STUDY}

F Foltran, P Berchialla, D Gregori*, A Pitkranta, I Slapak, J Jakubkov, L Bellussi, D Passali Correspondence: University of Padova, Via Loredan 18 Padova, 35100, Italy

10.1136/ip.2010.029215.781

Rationale and aim The insertion, inhalation, aspiration or ingestion of a foreign body (FB) is a relatively frequent event in young children. Some classes of objects such as stationery items (including pencils, pens and their parts etc), are frequently listed in clinical registries among commonly inserted, inhaled, aspirated or ingested objects but rarely receive a specific attention.

The aim of the present study is to characterise the risk of complications and prolonged hospitalisation due to stationery 